\title{
Inhibition of Collagenase and Stromelysin Gene Expression by Interferon- $\gamma$ in Human Dermal Fibroblasts Is Mediated in Part via Induction of Tryptophan Degradation
}

\author{
John Varga, * Tatyana Yufit, * and Raymond R. Brown* \\ *The Department of Medicine, Jefferson Medical College, Thomas Jefferson University, Philadelphia, Pennsylvania 19107;
} and ${ }^{\ddagger}$ the Cancer Center, University of Wisconsin, Madison, Wisconsin 53706

\begin{abstract}
The expression of the matrix-degrading enzymes collagenase and stromelysin is modulated by a variety of biologic and pharmacologic agents. IFN- $\boldsymbol{\gamma}$ has potent effects on metalloproteinase production and therefore may play an important role in preventing excessive connective tissue degradation during inflammation and repair. We investigated the mechanisms of collagenase and stromelysin regulation by IFN- $\gamma$ in human dermal fibroblasts. IFN- $\gamma(300 \mathrm{U} / \mathrm{ml})$ prevented the stimulation of metalloproteinase gene expression by IL-1 $\beta$. In addition, incubation of fibroblasts with IFN- $\gamma$ resulted in a marked increase in cellular indoleamine 2,3dioxygenase (IDO) mRNA, a $>90 \%$ depletion of tryptophan, and a corresponding $>30$-fold increase in the tryptophan metabolite kynurenine in the culture media. Reducing the concentration of tryptophan from $25 \mu \mathrm{M}$ to 0 markedly diminished the ability of fibroblasts to increase collagenase and stromelysin mRNA and collagenase production in re-

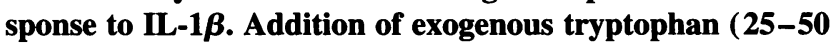
$\mu \mathrm{g} / \mathrm{ml}$ ) to cultures that had been tryptophan depleted by pretreatment with IFN- $\gamma$ for 48 h restored the fibroblast

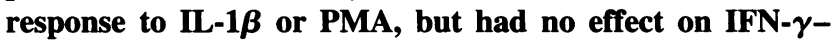
induced HLA-DR $\alpha$ chain mRNA expression. These results indicate that inhibition of collagenase and stromelysin gene expression by IFN- $\gamma$ in fibroblasts is associated with activation of IDO and enhanced cellular tryptophan metabolism. Tryptophan degradation and ensuing tryptophan depletion may account, at least in part, for the inhibitory effect of IFN$\gamma$ on metalloproteinase production in dermal fibroblasts. $(J$. Clin. Invest. 1995. 96:475-481.) Key words: collagenase • stromelysin • interferon- $\gamma$ - tryptophan - indoleamine 2,3dioxygenase
\end{abstract}

\section{Introduction}

A dynamic balance between the deposition and the degradation of connective tissue must be carefully maintained during physiologic tissue remodeling in development, angiogenesis, and

Address correspondence to Dr. John Varga, 509 Bluemle Life Sciences Building, Thomas Jefferson University, 233 South 10th Street, Philadelphia, PA 19107. Phone: 215-955-5042; FAX: 215-923-4649.

Received for publication 28 April 1994 and accepted in revised form 3 March 1995.

J. Clin. Invest.

(C) The American Society for Clinical Investigation, Inc. 0021-9738/95/07/0475/07\$2.00

Volume 96, July $1995,475-481$ wound healing. Alterations in connective tissue turnover are implicated in the degradation of the extracellular matrix $(\mathrm{ECM})^{1}$ characteristic of pathologic processes, including rheumatoid joint destruction, corneal ulcerations, and tissue invasion by tumors. Fibroblasts and other mesenchymal cells produce several structurally related endopeptidases that are capable of degrading the macromolecules of the ECM (reviewed in references 1 and 2). Interstitial collagenase, the prototypic member of the metalloproteinase family, initiates degradation of native interstitial collagens, whereas stromelysin degrades proteoglycans, laminin, and other matrix components and activates procollagenase in vitro. The production and activity of metalloproteinases are tightly regulated and can be modulated by various extracellular signals. IL- $\beta$ stimulates the expression of collagenase and stromelysin genes in a variety of cell types by a combination of transcriptional and posttranscriptional mechanisms (3-6). Additional inflammatory mediators, such as TNF$\alpha$ (7) and leukoregulin (8), are also potent physiologic stimuli for metalloproteinase production in fibroblasts and synovial cells. These cytokines are therefore pivotal in mediating connective tissue destruction in rheumatoid arthritis and related inflammatory conditions (9).

The interferon family of peptides are highly pleiotropic cytokines that exert immunomodulatory and antiproliferative effects on many cell types both in vitro and in vivo (10). IFN$\gamma$ is a product of activated T lymphocytes, macrophages, and natural killer cells. It has been shown to modulate the expression of genes for nitric oxide synthetase, tryptophanyl-tRNA synthetase, indoleamine 2,3-dioxygenase (IDO), and other proteins of unknown function (11-13). These gene products may be involved in mediating many of the biologic activities associated with IFN- $\gamma$ (14). In particular, IFN- $\gamma$-induced activation of IDO, which catalyzes tryptophan oxidation (15), is considered to be an important mechanism accounting for the antiproliferative effects of IFN- $\gamma$ on some tumor cells (16-19) and the inhibition of intracellular replication of parasites (20-23).

In addition to its well-recognized roles in the immune and inflammatory responses, IFN- $\gamma$ can also influence the metabolism of connective tissue cells. IFN- $\gamma$ regulates collagen accumulation by inhibiting the synthesis of types I and II collagens (24-26), abrogating the stimulatory effects of TGF- $\beta(27,28)$, and stimulating the expression of collagen receptors on fibroblasts (29). These effects have been shown to be mediated largely at the pretranslational level (25-28). IFN- $\gamma$ by itself, or in combination with inflammatory mediators, also has potent effects on the ability of fibroblasts and other cells to degrade

1. Abbreviations used in this paper: ECM, extracellular matrix; GAPDH, glyceraldehyde-3-phosphate dehydrogenase; IDO, indoleamine 2,3-dioxygenase. 
the surrounding $\operatorname{ECM}(30,31)$. The precise mechanisms involved in this potentially important function of IFN- $\gamma$ have not been fully characterized. In this study, we examined the regulation of metalloproteinase gene expression by IFN- $\gamma$ in cultured human fibroblasts and investigated whether modulation of IDO-mediated cellular tryptophan catabolism plays a role in mediating these effects. The results indicate that IFN- $\gamma$ prevented IL-1 $\beta$ - or PMA-stimulated collagenase and stromelysin gene expression in fibroblasts and caused a marked increase in IDO activity, resulting in depletion of tryptophan from the culture media. Repletion of tryptophan selectively reversed the IFN- $\gamma$-induced inhibition of metalloproteinase gene expression. Therefore, the inhibitory effects of IFN- $\gamma$ on IL- $1 \beta$-induced collagenase and stromelysin production in human fibroblasts appear to be mediated, at least in part, via induction of IDO and cellular tryptophan catabolism and the consequent depletion of tryptophan.

\section{Methods}

Reagents. All tissue culture reagents were obtained from Gibco Laboratories (Grand Island, NY). L-Tryptophan and PMA were obtained from Sigma Chemical Co. (St. Louis, MO). Recombinant human IL-1 $\beta$ and IFN- $\gamma$ were from Boehringer Mannheim Biochemicals (Indianapolis, IN). Methanol-water extracts of L-tryptophan used in these experiments were shown by HPLC to contain numerous peaks in addition to tryptophan; the concentration of each peak obtained was $<0.1 \%$, based on comparison of the peak area with the area of the tryptophan peak (Hill, R., personal communication). Therefore, the impurities in the tryptophan preparations represented by the peaks were present in the culture media at very low concentrations $(<250 \mathrm{nM})$ in these experiments.

Fibroblast cultures. The cell lines used in the present experiments were established from forearm skin biopsies of four healthy adults by explant techniques previously described (32). Cells were grown in MEM supplemented with $10 \%$ FCS, $1 \%$ vitamins, and $2 \mathrm{mM}$ L-glutamine (complete medium). When the cells reached visual confluence, fresh medium and 5\% FCS (extensively dialyzed against $0.05 \mathrm{M}$ Tris, $\mathrm{pH} 7.5,0.15 \mathrm{M} \mathrm{NaCl}$ to remove free amino acids) were added to the cultures. In selected experiments, tryptophan-free medium was used. IFN- $\gamma$ was added to cultures $24 \mathrm{~h}$ before IL- $1 \beta$ and/or exogenous tryptophan, unless otherwise noted. In previous experiments under similar conditions, we have found that neither IL- $1 \beta$ nor IFN- $\gamma$ had a significant effect on cell numbers in confluent cultures. Each experiment was performed at least twice, using different fibroblast lines. To determine total protein synthesis, $8 \mu \mathrm{Ci} / \mathrm{ml}\left[{ }^{35} \mathrm{~S}\right]$ cysteine and $\left[{ }^{35} \mathrm{~S}\right] \mathrm{me}$ thionine (EXPRE ${ }^{35} \mathrm{~S}^{35} \mathrm{~S}$ Protein Labeling Mix; DuPont, Wilmington, DE) were added to some cultures for the final $24 \mathrm{~h}$ of incubation. Cell viability was evaluated at the end of the incubation period by trypan blue staining and by measuring the release of lactate dehydrogenase into the culture media, as described previously (33), and by determining the incorporation of radiolabeled precursors into nondialyzable macromolecules in the culture supernatants.

Extraction and analysis of RNA. At the end of each experiment, total RNA was isolated from confluent fibroblasts by the $\mathrm{CsCl}$ centrifugation method (34) and subjected to Northern analysis using cDNAs previously labeled with $\left[\alpha-{ }^{32} \mathrm{P}\right] \mathrm{dCTP}$ by nick translation (35). Autoradiograms were analyzed by scanning at the linear range of the absorbance curve with a laser densitometer (LKB Wallac, Bromma, Sweden). The following cDNAs were used: human collagenase (36), HLA-DR $\alpha$ chain (37), and rat glyceraldehyde-3-phosphate dehydrogenase (GAPDH) (38), all obtained from the American Type Culture Collection (Rockville, MD); human stromelysin from Dr. C. Brinckerhof (Dartmouth Medical School, Hanover, NH) (39); and IDO from Dr. S. Gupta (Hipple Cancer Research Center, Dayton, OH) (40).

Determination of tryptophan and kynurenine concentrations. Total free tryptophan and kynurenine were assayed by HPLC on a C-18 column eluted isocratically using a solvent of $0.1 \mathrm{M}$ phosphate buffer (pH 3.6 with sodium hydroxide) containing $0.001 \mathrm{M}$ disodium-EDTA and $5 \%$ acetonitrile. Samples of culture media were deproteinized with perchloric acid $(0.6 \mathrm{M})$. Tryptophan was detected by its native fluorescence (activation at $290 \mathrm{~nm}$ and emission at $360 \mathrm{~nm}$ ) using a programmable fluorimeter (model HP1046A; Hewlett-Packard Co., Palo Alto, CA). Kynurenine was detected in the same chromatograms by ultraviolet absorption at $360 \mathrm{~nm}$ using a UV-1 absorbance detector (Rainin Instrument Co., Woburn, MA) in series with the fluorimeter. Chromatogram recordings and calculations were done using the Dynamax program (Rainin Instrument Co.).

Determination of collagenase levels. Competitive binding ELISAs for human fibroblast collagenase were performed on conditioned medium samples exactly as described previously (41). This assay measures active and latent, as well as free and bound (enzyme-substrate and enzyme-inhibitor complex) forms of collagenase.

\section{Results}

Effect of IFN- $\gamma$ on IL-1-induced collagenase and stromelysin $m R N A$ expression. To examine the effect of IFN- $\gamma$ on collagenase and stromelysin mRNA abundance, IFN- $\gamma$ and IL- $1 \beta$ were added to confluent dermal fibroblasts. Following a 24-h incubation, cultures were harvested, and mRNA levels were examined by Northern analysis. As shown in Fig. 1, untreated fibroblasts displayed very low levels of collagenase and stromelysin mRNAs. As reported previously (6), exposure of the cultures to $\mathrm{IL}-1 \beta$ for $24 \mathrm{~h}$ caused a marked increase in metalloproteinase mRNAs. Pretreatment with IFN- $\gamma$ reproducibly prevented the stimulatory effect of IL- $1 \beta$ in fibroblasts from three additional individuals. In contrast, IFN- $\gamma$ added to the cultures $24 \mathrm{~h}$ after IL- $1 \beta$ had only a slight inhibitory effect. After a 24 -h exposure to IFN- $\gamma$, some cultures were washed and incubated with fresh media containing IL- $1 \beta$ but no IFN- $\gamma$ for an additional $24 \mathrm{~h}$. As shown in Fig. 1, stimulation of collagenase and stromelysin mRNA expression in response to IL- $1 \beta$ remained incomplete $(\geq 60 \%$ lower than in cells not pretreated with IFN- $\gamma$ ) even after removal of IFN- $\gamma$ from the cultures.

Effect of IFN- $\gamma$ on tryptophan metabolism in fibroblast cultures. To determine whether abrogation of the IL- $1 \beta$-stimulated increase in collagenase and stromelysin mRNA expression by IFN- $\gamma$ was related to IDO induction, mRNA levels in IFN$\gamma$-treated fibroblast cultures were examined by Northern hybridization with human IDO cDNA (40). As shown in Fig. 2 $A$, IDO mRNA was essentially undetectable in untreated or in IL- $1 \beta$-treated cultures. Exposure of fibroblasts to IFN- $\gamma$ for $48 \mathrm{~h}$, in the presence or absence of IL- $1 \beta$, caused a marked increase in IDO mRNA levels. As expected, a single transcript with an apparent molecular size of $2.2 \mathrm{~kb}$ was observed. The stimulation of IDO mRNA by IFN- $\gamma$ was time and dose dependent, with a maximal effect after $\mathrm{a} \geq 8$-h incubation with $\geq 50$ $\mathrm{U} / \mathrm{ml}$ IFN- $\gamma$ (data not shown).

To examine the effects of IFN- $\gamma$ and IL- $1 \beta$ on IDO-mediated tryptophan metabolism in dermal fibroblasts, tryptophan and kynurenine were measured in the culture supernatants at the end of the incubation period. As shown in Fig. $2 \mathrm{~B}$, the tryptophan concentration in conditioned media from untreated cultures was slightly reduced compared with unconditioned MEM ( $10 \mu \mathrm{g} / \mathrm{ml}$; as indicated by the manufacturer), probably reflecting a low level of basal tryptophan degradation by fibroblasts. Addition of IL- $1 \beta$ to the cultures had no detectable effect on tryptophan or kynurenine concentrations in the media, whereas incubation with IFN- $\gamma$ caused a $>90 \%$ decrease in 

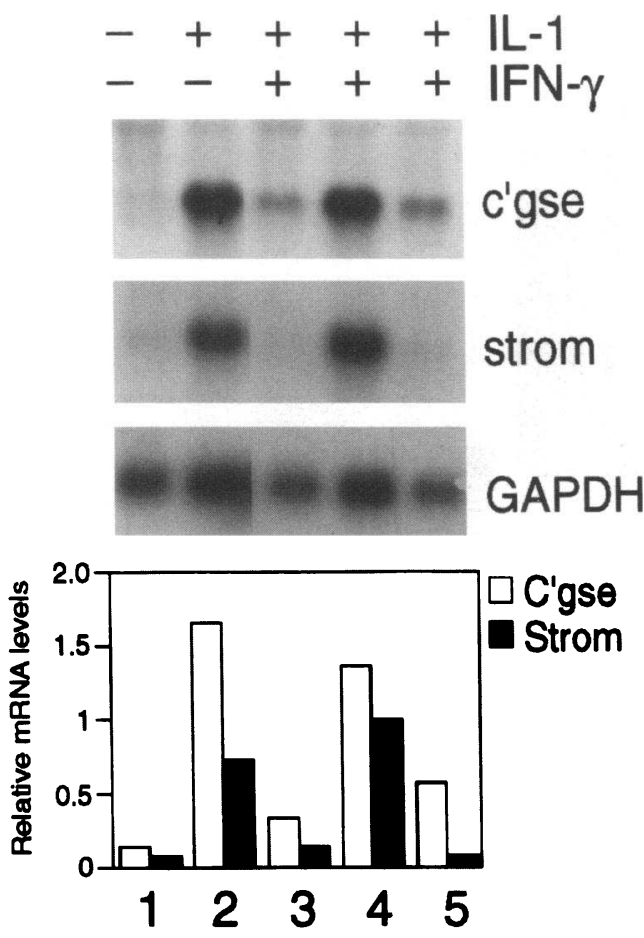

Figure 1. Modulation of IL- $1 \beta$-induced collagenase and stromelysin mRNA levels by IFN- $\gamma$. Confluent cultures of normal human dermal fibroblasts were incubated in medium supplemented with $5 \%$ FCS (complete medium). IFN- $\gamma(300 \mathrm{U} / \mathrm{ml})$ was added to the cultures $24 \mathrm{~h}$ before (lane 3 ) or $24 \mathrm{~h}$ after (lane 4$) \mathrm{IL}-1 \beta(1 \mathrm{ng} / \mathrm{ml})$. Controls included untreated cultures (lane 1 ) and cultures incubated with IL-1 $\beta$ alone (lane 2). In lane 5, cultures were washed after a 24-h exposure to IFN$\gamma$ and then incubated with fresh medium containing IL- $1 \beta$ but no IFN$\gamma$ for an additional $24 \mathrm{~h}$. The steady-state mRNA levels were determined at the end of the incubation period by Northern hybridization ( $10 \mu \mathrm{g}$ per lane) to ${ }^{32} \mathrm{P}$-labeled collagenase ( $c$ 'gse), stromelysin (strom), and GAPDH cDNAs as described in Methods (upper panels). The abundance of mRNA was quantitated by scanning densitometry of the autoradiograms, and the values are shown after correction for variations in GAPDH mRNA levels (lower panel).

tryptophan and a $>30$-fold increase in kynurenine concentrations. Tryptophan concentrations were reduced in the culture media even when IFN- $\gamma$ was present in the cultures only for the first $24 \mathrm{~h}$ of a 48 -h incubation period. These findings indicate that IFN- $\gamma$ caused a sustained increase in cellular IDO gene expression, resulting in markedly enhanced catabolism of tryptophan and consequent depletion of this essential amino acid from the culture media.

Effect of tryptophan depletion on IL-1 $\beta$-induced collagenase and stromelysin gene expression. The finding that abrogation of IL- $1 \beta$-induced collagenase and stromelysin gene expression by IFN- $\gamma$ was accompanied by elevation of IDO mRNA and consequent tryptophan depletion in the culture media suggested that the concentration of tryptophan may modulate some of the effects of IL- $1 \beta$ on dermal fibroblasts. To examine directly the influence of tryptophan on metalloproteinase gene expression, fibroblasts were switched from complete media to tryptophan-free media and 5\% dialyzed FCS at confluence. After $18 \mathrm{~h}$, the cultures received IL-1 $\beta(2 \mathrm{ng} / \mathrm{ml})$ and tryptophan ( 1 or $25 \mu \mathrm{M}$ ) for an additional $24 \mathrm{~h}$ of incubation. There were no differences in cellular morphology under the phase contrast microscope or in viability, as determined by release of lactate dehydrogenase into the media by fibroblasts maintained in tryptophan-free and tryptophan-containing cultures. By trypan blue dye exclusion, the cultures consistently yielded $>90 \%$ viability, and the incorporation of radiolabeled precursors into newly synthesized macromolecules was unaffected by the absence of tryptophan in the cultures for up to 96 $\mathrm{h}$, demonstrating that tryptophan deprivation did not result in significant toxicity to the fibroblasts. Northern analysis of total RNA from untreated and IL- $1 \beta$-treated fibroblasts indicated that stimulation of collagenase and stromelysin mRNA by IL$1 \beta$ was markedly reduced in the cultures under tryptophan-free conditions (Fig. $3 A$ ). In contrast, GAPDH mRNA levels were similar in the presence or absence of tryptophan in the media. Identical results were obtained from two separate experiments.

Secreted collagenase was measured by ELISA in cultures of untreated or IL- $1 \beta$-treated fibroblasts that had been placed at confluence in tryptophan-free media, or in media with tryptophan. As shown in Fig. $3 \mathrm{~B}$, in media with $25 \mu \mathrm{M}$ tryptophan, unstimulated fibroblasts released small amounts $(29 \mathrm{ng} / \mathrm{ml})$ of collagenase, and addition of IL- $1 \beta$ to the cultures induced a 65 fold increase in collagenase production. Under tryptophan-free conditions, fibroblasts released $15 \mathrm{ng} / \mathrm{ml}$ collagenase during the incubation period and stimulation with IL-1 $\beta$ resulted in a 23fold increase. These results demonstrate that lowering the concentration of tryptophan progressively interfered with the ability of confluent fibroblasts to respond to $\mathrm{IL}-1 \beta$ by increasing collagenase production and mRNA, without adversely affecting cellular viability.

Effect of tryptophan repletion of IFN- $\gamma$-treated cultures on the response to $I L-1 \beta$. Since IFN- $\gamma$ induced the degradation of tryptophan in the cultures and fibroblasts under tryptophanfree conditions displayed reduced responsiveness to IL- $1 \beta$, we speculated that abrogation of IL- $\beta$-induced metalloproteinase synthesis and mRNA expression by IFN- $\gamma$ was in part due to tryptophan depletion. To test this hypothesis, we examined whether addition of exogenous tryptophan to IFN- $\gamma$-treated tryptophan-depleted cultures would restore full fibroblast responsiveness to IL- $\beta$-induced collagenase and stromelysin gene expression. For this purpose, IFN- $\gamma$ was added to confluent fibroblasts that were maintained in complete media, followed $48 \mathrm{~h}$ later by the addition of various concentrations of tryptophan. $24 \mathrm{~h}$ later, IL-1 $\beta$ was added and the incubation was continued for an additional $32 \mathrm{~h}$. As shown in Fig. 4 (top), IL$1 \beta$ caused an increase in collagenase and stromelysin mRNA, whereas pretreatment of cultures with IFN- $\gamma$ reduced this stimulation by $>80 \%$. Treatment with IFN- $\gamma$ for $48 \mathrm{~h}$ also caused a $>90 \%$ decrease in the concentration of tryptophan in the culture media (data not shown). In the presence of increasing concentrations of tryptophan, addition of IL- $1 \beta$ to the IFN- $\gamma-$ treated cultures caused a progressive increase in collagenase and stromelysin mRNA, such that $50 \mu \mathrm{g} / \mathrm{ml}$ tryptophan completely overcame the IFN- $\gamma$-induced inhibition (Fig. 4, top). In the absence of IL- $1 \beta$, addition of tryptophan to untreated or IFN$\gamma$-treated cultures appeared to have no effect on collagenase or stromelysin mRNA levels. To control for nonspecific effects of tryptophan, mRNA was hybridized to DR1, a cDNA for the human HLA-DR $\alpha$ chain (37). The marked increase in HLADR $\alpha$ chain mRNA expression induced by IFN- $\gamma$ in the presence or absence of IL- $1 \beta$ was unaltered by addition of tryptophan to the cultures (data not shown). Therefore, exogenous 


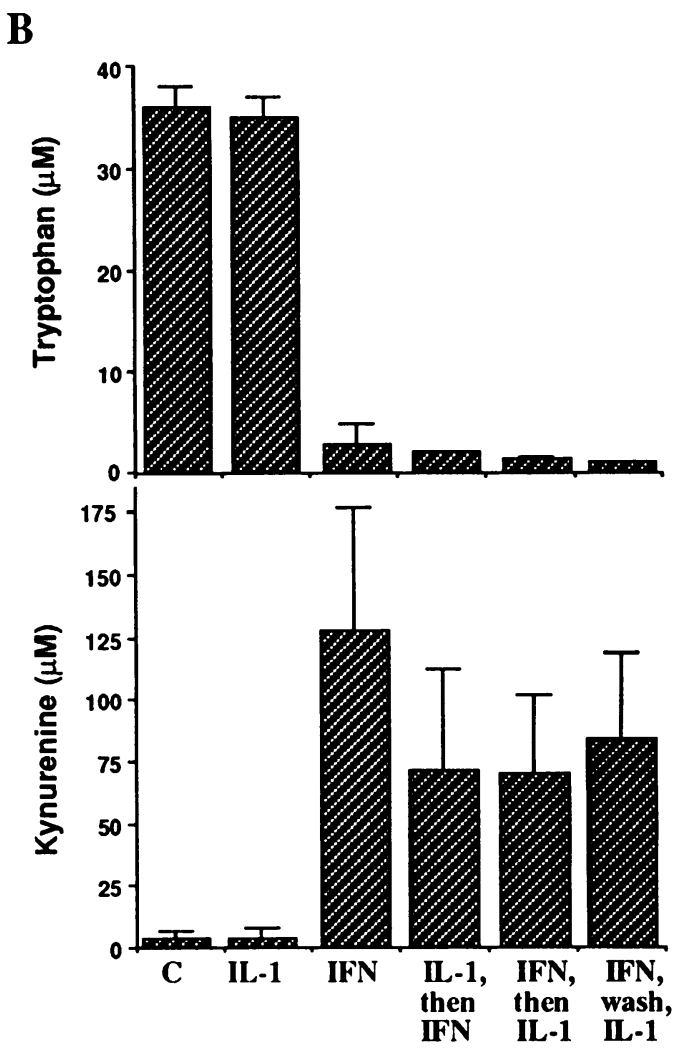

Figure 2. Effect of IFN- $\gamma$ on IDO mRNA expression and IDO enzyme activity in skin fibroblasts. $(A)$ Representative autoradiogram. Confluent dermal fibroblasts were incubated in complete medium. IFN- $\gamma(300 \mathrm{U} / \mathrm{ml})$ was added to the cultures alone (lane 3$), 24 \mathrm{~h}$ after (lane 4$), 24 \mathrm{~h}$ before (lane 5), or simultaneously (lane 6 ) with $1 \mathrm{ng} / \mathrm{ml} \mathrm{IL-1} \beta$. Controls consisted of untreated cultures (lane 1 ) and cultures treated with IL-1 $\beta$ alone (lane 2). At the end of the incubation period, the levels of mRNA were examined by Northern hybridization to human IDO and GAPDH cDNAs as described in Methods. The size of the IDO mRNA is $\sim 2.2 \mathrm{~kb}$. (B) Quantitation of tryptophan and kynurenine levels in the culture media. Concentrations of tryptophan and kynurenine were measured in the conditioned media at the end of the incubation period, as described in Methods. Results represent the mean \pm SEM from three separate experiments. $C$, control cultures.

tryptophan did not interfere with the fibroblast response to IFN$\gamma$ in a nonspecific manner.

Quantitation of collagenase in the conditioned media by ELISA indicated that pretreatment of the cultures with IFN- $\gamma$ caused $\mathrm{a}>70 \%$ reduction in the IL- $1 \beta$-induced stimulation of collagenase production (Fig. 5). Addition of tryptophan to cultures treated with IFN- $\gamma$ plus IL- $1 \beta$ restored the ability of fibroblasts to produce large quantities of collagenase. Exogenous tryptophan overcame the inhibitory effects of IFN- $\gamma$ on upregulated collagenase and stromelysin mRNA expression induced not only by IL- $1 \beta$, but also by the tumor promoter PMA at $160 \mathrm{nM}$ (data not shown).

\section{Discussion}

In pathologic conditions, quiescent mesenchymal cells attain a matrix-degrading phenotype upon their interaction with inflammatory cells. Inflammatory cell-derived cytokines, alone or in combination, regulate the production and activity of matrix-degrading enzymes and are therefore considered to play a central role in the initiation of connective tissue degradation (9). The present results demonstrate that in human dermal fibroblasts, IFN- $\gamma$ prevented the increase in collagenase and stromelysin mRNA and collagenase production induced by IL- $1 \beta$.
The inhibitory effect was maximal when cultures were exposed to IFN- $\gamma$ before IL- $1 \beta$, suggesting that fibroblasts needed to be primed for IL- $1 \beta$ resistance. These results, which are consistent with a previous report (30), indicate that IFN- $\gamma$ exerts sustained negative effects on the production and activity of matrix-degrading enzymes and suggest that IFN- $\gamma$ may play an important role in preventing excessive connective tissue degradation in physiologic conditions.

Activation of transcription by IFN- $\gamma$ has been extensively studied (14), but the inhibitory effects of this cytokine on gene expression are less well understood. To investigate the mechanisms by which IFN- $\gamma$ prevented IL- $1 \beta$-induced expression of metalloproteinase genes in fibroblasts, we examined the regulation of IDO by these cytokines. IDO (EC 1.13.11.17), an enzyme widely distributed in mammalian extrahepatic tissues, catalyzes the first step in the degradation of tryptophan (42). This step, involving the incorporation of molecular oxygen or superoxide anion, results in decylization of the tryptophan pyrrole ring and formation of $N$-formylkynurenine $(16,43)$. We found that whereas treatment of the fibroblasts with IL- $1 \beta$ had no effect on IDO mRNA levels, IFN- $\gamma$ by itself or in combination with IL- $1 \beta$ caused a marked increase. IFN- $\gamma$ was previously shown to activate the transcription of IDO in human fibroblasts $(13,44)$. Although the biologic significance of IDO induction is 

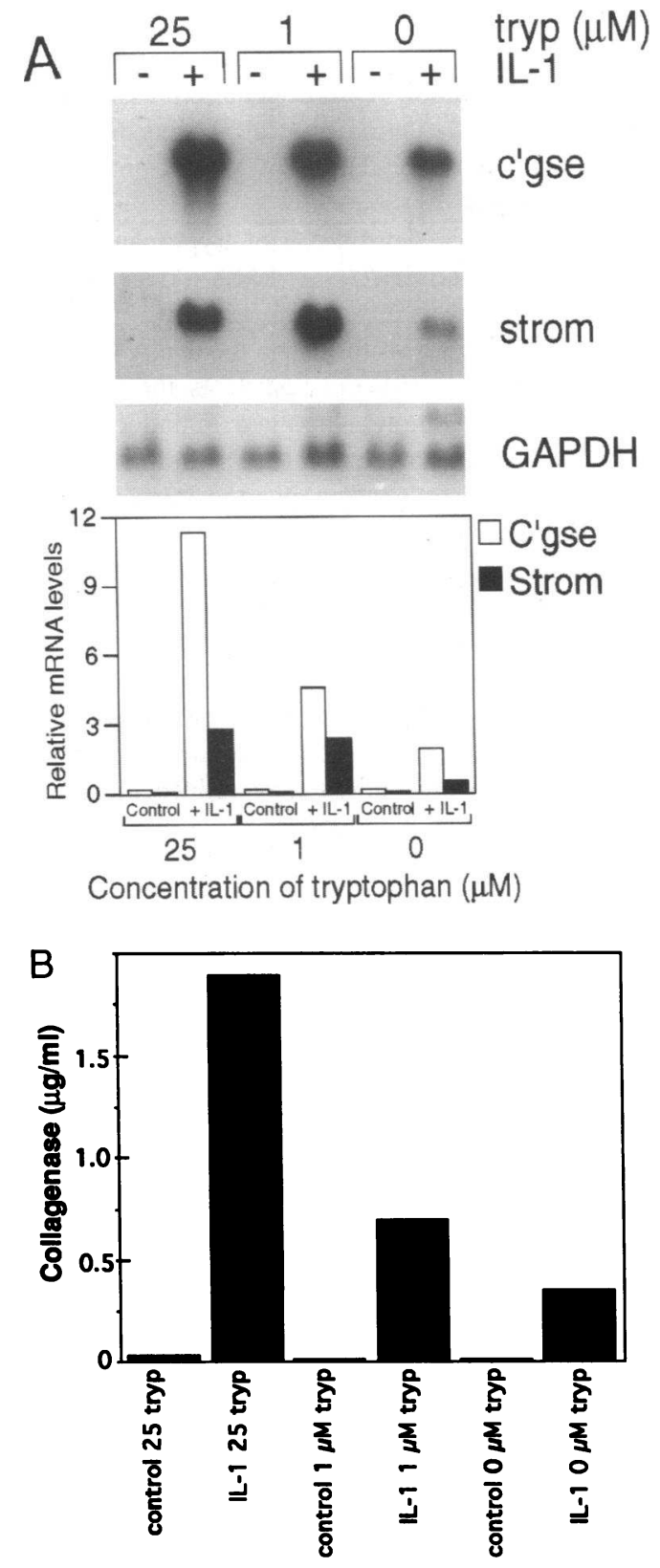

Figure 3. Effect of tryptophan concentration on fibroblast response to IL-1 $\beta$. Dermal fibroblasts were maintained in complete medium and then switched to tryptophan-free medium and 5\% FCS at confluence. After $18 \mathrm{~h}, \mathrm{IL}-1 \beta(2 \mathrm{ng} / \mathrm{ml})$ and tryptophan ( 1 or $25 \mu \mathrm{M})$ were added. At the end of an additional 24-h incubation, cultures were harvested. (A) Total RNA was analyzed by Northern hybridization with collagenase (c'gse), stromelysin (strom), and GAPDH cDNA (upper panel). Collagenase and stromelysin mRNA abundance was quantitated, and the values are shown after correction for variations in GAPDH mRNA levels (lower panel). (B) Secreted collagenase at the end of the incubation period was measured in the conditioned culture media by ELISA, as described in Methods.

unknown, it has been suggested that it represents an antioxidant defense mechanism during the inflammatory response (45). After exposure to IFN- $\gamma$, the uptake and IDO-mediated intracellular oxidation of tryptophan are dramatically increased in cultured mammalian cells (20). The effect is specific for trypto-

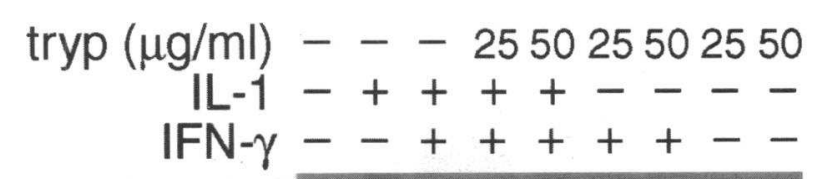

c'gse
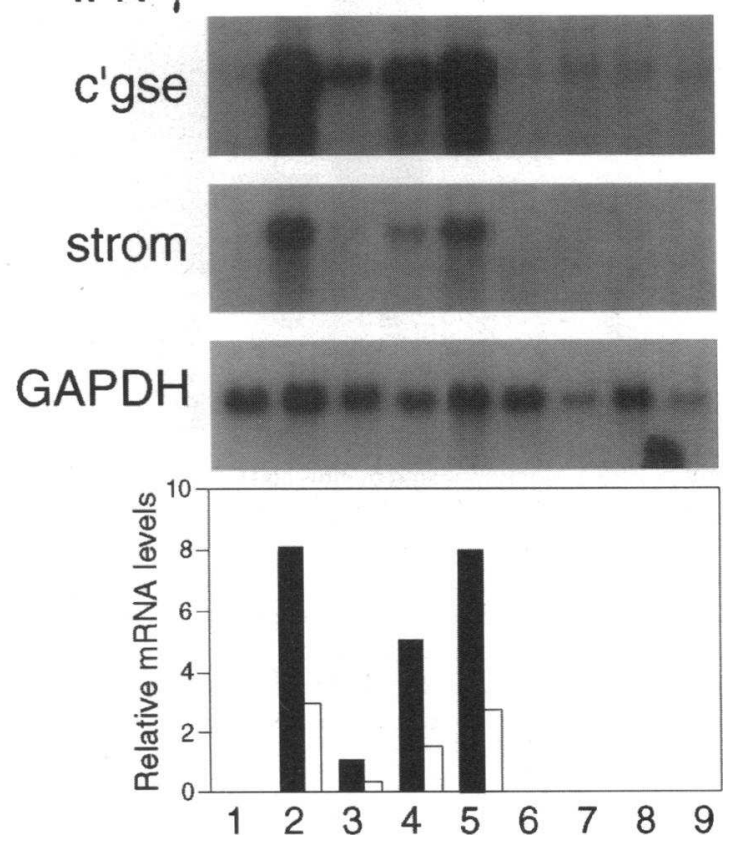

Figure 4. Effect of repletion of tryptophan on the ability of IFN- $\gamma-$ treated fibroblasts to respond to IL- $1 \beta$. Fresh medium with or without IFN- $\gamma(300 \mathrm{U} / \mathrm{ml})$ was added to confluent dermal fibroblasts. $48 \mathrm{~h}$ later, the indicated amounts of tryptophan were added (lanes 4-7), followed $24 \mathrm{~h}$ later by the addition of IL- $1 \beta(2 \mathrm{ng} / \mathrm{ml}$ ) (lanes $2-5)$. Control cultures were left untreated (lane 1 ) or exposed to tryptophan only (lanes 8 and 9). At the end of an additional 32-h incubation, the cultures were harvested. Total RNA was analyzed by Northern hybridization with collagenase ( $c$ 'gse), stromelysin (strom), and GAPDH cDNA. The abundance of collagenase and stromelysin mRNA was quantitated, and the values are shown after correction for variations in GAPDH mRNA levels (lower panel). Similar results were obtained from three separate experiments. Solid bars, collagenase; open bars, stromelysin.

phan, as neither the intracellular transport nor the degradation of other amino acids is significantly effected by IFN- $\gamma(46)$. Induction of selective tryptophan degradation by IFN- $\gamma$ has also been demonstrated in vivo (47). In the present studies, IFN- $\gamma$ caused a $>90 \%$ decrease in tryptophan and a parallel 30 -fold increase in kynurenine concentrations in the culture media, indicating a marked enhancement of IDO-catalyzed tryptophan metabolism. Since changes in the intracellular pool of tryptophan follow closely the changes in the extracellular pool in IFN- $\gamma-$ treated fibroblasts (46), our findings suggest that treatment with IFN- $\gamma$ resulted in tryptophan deprivation in these cells.

Because the inhibitory effects of IFN- $\gamma$ on metalloproteinase production were accompanied by induction of IDO and increased tryptophan catabolism, we speculated that depletion of tryptophan interfered with the ability of fibroblasts to activate metalloproteinase gene transcription in response to IL- $1 \beta$. To test this hypothesis, we first examined whether the concentration of tryptophan in the culture media influenced IL- $1 \beta$-stimulated collagenase and stromelysin expression. The results indicated that the magnitude of stimulation by $\mathrm{IL}-1 \beta$ was markedly reduced, both at the mRNA and protein levels, in tryptophan-free 


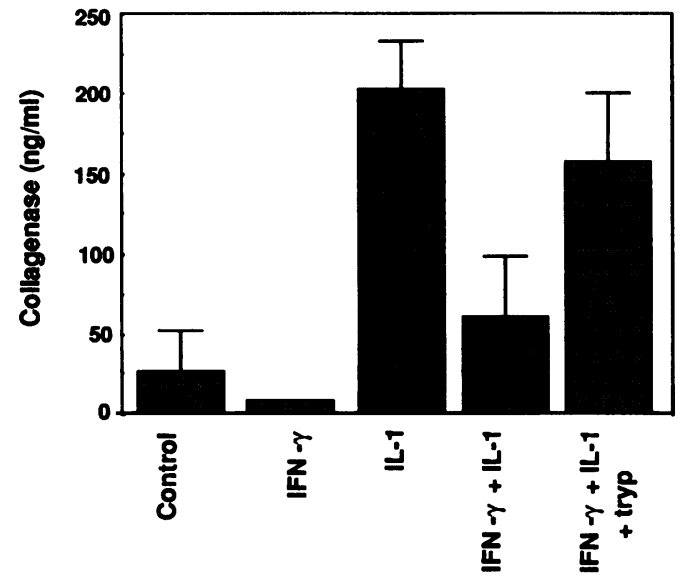

Figure 5. Effect of tryptophan repletion on IL-1 $\beta$-stimulated collagenase production by IFN- $\gamma$-treated fibroblasts. At confluence, IFN- $\gamma(200$ $\mathrm{U} / \mathrm{ml}$ ) was added to dermal fibroblasts maintained in complete medium, followed $24 \mathrm{~h}$ later by IL-1 $\beta$ and tryptophan. Control cultures received IL- $1 \beta$ or IFN- $\gamma$ alone or in combination, or were left untreated. Conditioned media were collected at the end of a 48-h incubation, and secreted collagenase was quantitated by ELISA, as described in Methods. The results shown represent the mean \pm SEM from three separate experiments.

cultures compared with cultures in MEM $(10 \mu \mathrm{g} / \mathrm{ml}$ tryptophan). To confirm further the role of tryptophan, we examined whether repletion of tryptophan in cultures rendered tryptophanfree by IFN- $\gamma$ treatment could restore the full effect of IL- $1 \beta$ on metalloproteinase gene expression. The results showed that addition of tryptophan to fibroblasts pretreated with IFN- $\gamma$ reversed the inhibitory effects of IFN- $\gamma$, while having no effect on IFN- $\gamma$-induced HLA-DR $\alpha$ chain mRNA levels.

Taken together, these results strongly suggest that tryptophan is required for maximal stimulation of collagenase and stromelysin gene expression in dermal fibroblasts. Although it is the least abundant amino acid in mammalian proteins, tryptophan serves as a metabolic precursor for biologically important amines (see reference 48 for review) and has been shown to stimulate protein synthesis independent of its function as a precursor amino acid (49-51). We recently reported that at supraphysiologic concentrations ( $\geq 500 \mu \mathrm{g} / \mathrm{ml}$ ), tryptophan, but not other amino acids, caused transcriptional stimulation of collagenase gene expression in human fibroblasts (33). Since tryptophan appears to be important in the regulation of several biologic processes, IDO-mediated cellular tryptophan catabolism and the ensuing tryptophan starvation may have pleiotropic effects. Indeed, the antiproliferative activity of IFN- $\gamma$ on some tumor cells can be attributed to the intracellular depletion of tryptophan (16-19). Similarly, the inhibitory effects of IFN- $\gamma$ on the intracellular growth of certain parasites, such as Toxoplasma gondii in human fibroblasts and glioblastoma cells (20, 22 ) and Chlamydia psittaci in human macrophages and bladder carcinoma cell lines $(21,23)$, appear to be due, at least in part, to enhanced IDO-mediated tryptophan catabolism in the host cells. Overexpression of IDO in a transformed human fibroblast line markedly inhibited the proliferation of transfected cells, and this effect was correlated with depletion of tryptophan from the media (52). Furthermore, in mutant ME180 human cervical carcinoma lines, which are deficient in IDO activity and therefore unable to catabolize tryptophan, IFN- $\gamma$ failed to inhibit cellular proliferation or the intracellular growth of Chlamydia or Toxoplasma $(53,54)$. Our findings extend these observations by demonstrating that activation of IDO gene expression and the consequent tryptophan depletion may also be responsible for the IFN- $\gamma$-induced downregulation of metalloproteinase production in human dermal fibroblasts.

The mechanism by which deprivation of tryptophan in fibroblast cultures interferes with IL- $\beta$ - or PMA-induced collagenase and stromelysin gene expression is unknown. Tryptophan may be required for the synthesis or the DNA-binding activity of nuclear transcription factors, such as the jun and fos members of the AP-1 complex involved in induction of collagenase and stromelysin transcription $(5,7)$. In this regard, it is of great interest that conserved tryptophan residues (tryptophan clusters) have been shown to be necessary for the sequence-specific DNA binding activity of the c-myb protooncogene product (55). Regardless of the molecular mechanisms involved, the present findings shed new light on the modulation of connective tissue turnover by IFN- $\gamma$. Furthermore, these observations raise the possibility that pharmacologic modulation of the tryptophan concentration in tissues undergoing cytokinemediated connective tissue breakdown may reduce the local expression of matrix-degrading enzymes.

\section{Acknowledgments}

The authors thank Ms. K. Fliszar for performing collagenase ELISAs, Dr. J. Snyder for determining lactate dehydrogenase release, and Dr. G. Dodge and Dr. A. Mauviel for valuable suggestions.

This study was supported by National Institutes of Health grants AR-42309 and AR-01817 and by a research grant from Showa-Denko Inc., Tokyo.

\section{References}

1. Matrisian, L. 1992. The matrix-degrading metalloproteinases BioEssay. 14:455-463.

2. Woessner, J. 1992. Matrix metalloproteinases and their inhibitors in connective tissue remodeling. FASEB (Fed. Am. Soc. Exp. Biol.) J. 5:2145-2154.

3. Postlethwaite, A., L. Lachman, C. Mainardi, and A. H. Kang. 1983. Interleukin 1 stimulation of collagenase production in cultured fibroblasts. J. Exp. Med. 157:801-806.

4. Circolo, A., H. Welgus, G. Pierce, J. Kramer, and R. Strunk. 1991. Differential regulation of the expression of proteinases/antiproteinases in fibroblasts: effects of IL-1 and platelet-derived growth factor. J. Biol. Chem. 266:12283-12288.

5. Quinones, S., J. Saus, Y. Otani, E. D. Harris, Jr., and M. Kurkinen. 1989. Transcriptional regulation of human stromelysin. J. Biol. Chem. 264:8339-8344.

6. Vincenti, M. P., C. I. Coon, O. Lee, and C. E. Brinckerhoff. 1994. Regulation of collagenase gene expression by $\mathrm{IL}-1 \beta$ requires transcriptional and posttranscriptional mechanisms. Nucleic Acids Res. 22:4818-4827.

7. Brenner, D., M. O’Hara, P. Angel, M. Chojkier, and M. Karin. 1989. Prolonged activation of jun and collagenase genes by tumor necrosis factor. Nature (Lond.). 348:661-663.

8. Mauviel, A., V.-M. Kahari, C. Evans, and J. Uitto. 1992. Transcriptional activation of fibroblast collagenase gene expression by a novel lymphokine, leukoregulin. J. Biol. Chem. 267:5644-5468.

9. Brinckerhoff, C. 1991. Joint destruction in arthritis: metalloproteinases in the spotlight. Arthritis Rheum. 34:1073-1076.

10. De Mayer, E., and J. De Mayer-Guignard. 1988. Interferons and Other Regulatory Cytokines. John Wiley \& Sons, Inc., New York.

11. Karupiah, G., Q. Xie, M. L. Buller, C. Nathan, C. Duarte, and J. D. MacMicking. 1993. Inhibition of viral replication by interferon- $\gamma$-induced nitric oxide synthase. Science (Wash. DC). 261:1445-1447.

12. Rubin, B. Y., S. L. Anderson, L. Xing, R. J. Powell, and W. P. Tate. 1991. Interferon induces tryptophanyl-tRNA synthetase expression in human fibroblasts. J. Biol. Chem. 266:24245-24248.

13. Dai, W., and S. L. Gupta. 1990. Regulation of indoleamine 2,3-dioxygenase gene expression in human fibroblasts by interferon- $\gamma$. J. Biol. Chem. 265:19871-19877. 
14. Williams, B. 1991. Transcriptional regulation of interferon-stimulated genes. Eur. J. Biochem. 200:1-11.

15. Shimizu, T., S. Nomiyama, and O. Hayaishi. 1978. Indoleamine 2,3dioxygenase: purification and some properties. J. Biol. Chem. 253:4700-4706.

16. Takikawa, O., T. Kuroiwa, F. Yamazaki, and R. Kido. 1988. Mechanisms of interferon- $\gamma$ action. J. Biol. Chem. 263:2041-2048.

17. Aune, T., and S. Pogue. 1989. Inhibition of tumor cell growth by interferon- $\gamma$ is mediated by two distinct mechanisms dependent upon oxygen tension. Induction of tryptophan degradation and depletion of intracellular nicotinamide adenine dinucleotide. J. Clin. Invest. 84:863-875.

18. de la Maza, L. M., and E. Peterson. 1988. Dependence of the in vitro antiproliferative activity of recombinant human interferon- $\gamma$ on the concentration of tryptophan in the culture media. Cancer Res. 48:346-350.

19. Ozaki, Y., M. P. Edelstein, and D. S. Duch. 1988. Induction of indoleamine 2,3-dioxygenase: a mechanism of the antitumor activity of IFN- $\gamma$. Proc. Natl. Acad. Sci. USA. 85:215-219.

20. Pfefferkorn, E. R. 1984. Interferon- $\gamma$ blocks the growth of Toxoplasma gondii in human fibroblasts by inducing the host cell to degrade tryptophan. Proc. Natl. Acad. Sci. USA. 81:908-912.

21. Byrne, G., L. Lehman, and G. Landry. 1986. Induction of tryptophan catabolism is the mechanism for interferon- $\gamma$-mediated inhibition of intracellular Chlamydia psittaci replication in T24 cells. Infect. Immun. 53:347-351.

22. Daubener, W., K. Pilz, S. S. Zennati, T. Bilzer, H. Fischer, and U. Hadding. 1993. Induction of toxoplasmostasis in a human glioblastoma by interferon- $\gamma . J$. Neuroimmunol. 43:31-38.

23. Gupta, S. L., J. M. Carlin, P. Pyati, W. Dai, E. R. Pfefferkorn, and M. J. Murphy, Jr. 1994. Antiparasitic and antiproliferative effects of indoleamine 2,3dioxygenase enzyme expression in human fibroblasts. Infect. Immun. 62:22772284.

24. Amento, E. P., A. K. Bhan, K. G. McCullargh, and S. M. Krane. 1985. Influences of interferon-gamma on synovial fibroblast-like cells: Ia induction and inhibition of collagen synthesis. J. Clin. Invest. 76:837-848.

25. Czaja, M., F. Weiner, M. Eghbali, M.-A. Giamborne, M. Eghbali, and M. Zern. 1987. Differential effects of $\gamma$-interferon on collagen and fibronectin gene expression. J. Biol. Chem. 262:13348-13351.

26. Reginato, A., C. Sanz-Rodriguez, A. Diaz, R. Dharmavaram, and S. Jimenez. 1993. Transcriptional modulation of cartilage-specific collagen gene expression by interferon- $\gamma$ and tumour necrosis factor- $\alpha$ in cultured human chondrocytes. Biochem. J. 294:761-769.

27. Varga, J., A. Olsen, J. Herhal, G. Constantine, J. Rosenbloom, and S. A. Jimenez. 1990. Interferon- $\gamma$ reverses the stimulation of collagen but not fibronectin gene expression by transforming growth factor $\beta$ in normal human fibroblasts. Eur. J. Clin. Invest. 20:487-493.

28. Kahari, V.-M., Y. Chen, M. Su, and J. Uitto. 1990. Tumor necrosis factor- $\alpha$ and interferon- $\gamma$ suppress the activation of human type I collagen gene expression by transforming growth factor $\beta 1$. J. Clin. Invest. 86:1489-1494.

29. Clark, J. G., T. F. Dedon, E. A. Wayner, and W. G. Carter. 1989. Effects of interferon- $\gamma$ on cell surface receptors for collagen and deposition of newly synthesized collagen by cultured human lung fibroblasts. J. Clin. Invest. 83:15051511.

30. Shapiro, S. D., E. J. Campbell, D. K. Kobayashi, and H. G. Welgus. 1990. Immune modulation of metalloproteinase production in human macrophages. Selective pretranslational suppression of interstitial collagenase and stromelysin biosynthesis by interferon- $\gamma$. J. Clin. Invest. 86:1204-1210.

31. Unemori, E. N., M. J. Bair, E. A. Bauer, and E. P. Amento. 1991. Stromelysin expression regulates collagenase activation in human fibroblasts. J. Biol. Chem. 266:23477-23482.

32. Varga, J., J. Rosenbloom, and S. A. Jimenez. 1987. Transforming growth factor- $\beta$ causes a persistent increase in steady-state levels of type I and type III collagen and fibronectin mRNAs in human dermal fibroblasts. Biochem. J. 247:597-604.

33. Varga, J., L. Li, A. Mauviel, J. Jeffrey, and S. A. Jimenez. 1994. LTryptophan in supraphysiologic concentrations stimulates collagenase gene expression in human skin fibroblasts. Lab. Invest. 70:183-191.

34. Chirgwin, J., A. Pryzbyla, R. MacDonald, and W. Rutter. 1979. Isolation of biologically active ribonucleic acid from sources enriched in ribonuclease. Biochemistry. 18:5293-5299.

35. Sambrook, J., E. Fritsch, and T. Maniatis. 1989. Molecular Cloning: A Laboratory Manual. 2nd ed. Cold Spring Harbor, NY, Cold Spring Harbor Laboratory. 7.3-7.39.

36. Angel, P., I. Bauman, B. Stein, H. Delius, H. J. Rahmsdorf, and P. Herrlich. 1987. 12-O-Tetradecanoyl-phorbol-13-acetate induction of human collagenase gene is mediated by an inducible element located in the $5^{\prime}$ flanking region. $\mathrm{Mol}$. Cell. Biol. 7:2256-2264.

37. Sekaly, R. P., C. Tonelle, M. Strubin, B. Mach, and E. O. Long. 1986. Cell surface expression of class II histocompatibility antigens occurs in the absence of the invariant chain. J. Exp. Med. 164:1490-1504.

38. Fort, P., L. Marty, M. Pichazyk, S. ElSabrouty, P. Jeanteur, and J. Blanchard. 1985. Various rat adult tissues express only one major mRNA species from the glyceraldehyde-3-phosphate dehydrogenase family. Nucleic Acids Res. 13:1431-1442.

39. Sirum, K., and C. Brinckerhoff. 1989. Cloning of the genes for human stromelysin and stromelysin-2: differential expression in rheumatoid synovial fibroblasts. Biochemistry. 28:8691-8698.

40. Dai, W., and S. L. Gupta. 1990. Molecular cloning, sequencing and expression of human interferon- $\gamma$-inducible indoleamine 2,3-dioxygenase cDNA. Biochem. Biophys. Res. Commun. 168:1-8.

41. Cooper, T. W., E. A. Bauer, and A. Z. Eisen. 1982. Enzyme-linked immunosorbent assay for human skin collagenase. Collagen Relat. Res. 3:205216.

42. Taylor, M. W., and G. Feng. 1991. Relationship between interferon- $\gamma$, indoleamine 2,3-dioxygenase, and tryptophan catabolism. FASEB (Fed. Am. Soc. Exp. Biol.) J. 5:2516-2522.

43. Taniguchi, T., F. Hirata, and O. Hayaishi. 1977. Intracellular utilization of superoxide anion by indoleamine 2,3-dioxygenase of rabbit enterocytes. $J$. Biol. Chem. 252:2774-2776.

44. Caplen, H. S., and S. L. Gupta. 1988. Differential regulation of a cellular gene by human interferon- $\gamma$ and interferon- $\alpha$. J. Biol. Chem. 263:332-339.

45. Christen, S., E. Peterhans, and R. Stocker. 1990. Antioxidant activities of some tryptophan metabolites: possible implication for inflammatory disease. Proc. Natl. Acad. Sci. USA. 87:2506-2510.

46. Turco, J., and H. H. Winkler. 1986. Gamma-interferon-induced inhibition of the growth of Rickettsia prowazekii in fibroblasts cannot be explained by degradation of tryptophan or other amino acids. Infect. Immun. 53:38-46.

47. Byrne, G. I., L. Lehman, J. G. Kirschbaum, E. C. Borden, C. M. Lee, and R. R. Brown. 1986. Induction of tryptophan degradation in vivo and in vitro, a $\gamma$-interferon-stimulated activity. J. Interferon Res. 6:389-398.

48. Peters, J. 1991. Tryptophan metabolism and nutrition: an overview. In Kynurenine and Serotonin Pathways. R. Schwarcz, S. N. Young, and R. R. Brown, editors. Plenum Press, New York. 345-358.

49. Sidransky, H., C. N. Murty, and E. Verney. 1984. Nutritional control of protein synthesis: studies relating to tryptophan-induced stimulation of nucleocytoplasmic translocation of mRNA in the liver. Am. J. Pathol. 117:298-309.

50. Wang, D., E. Verney, R. Kurl, and H. Sidransky. 1987. Effect of tryptophan on isolated hepatocytes of rats. Virchow Arch. B. 53:125-132.

51. Lin, F. D., T. K. Smith, and H. S. Bayley. 1988. The role for tryptophan in regulation of protein synthesis in porcine muscle. J. Nutr. 118:445-449.

52. Gupta, S., J. M. Carlin, P. Pyati, W. Dai, E. R. Pfefferkorn, and M. J. Murphy. 1994. Antiparasitic and antiproliferative effects of indoleamine 2,3-dioxygenase enzyme expression in human fibroblasts. Infect. Immun. 62:2277-2284.

53. Feng, G. S., and M. W. Taylor. 1989. IFN- $\gamma$ resistant mutants are defective in the induction of indoleamine 2,3-dioxygenase. Proc. Natl. Acad. Sci. USA. 86:7144-7148.

54. Thomas, S. M., L. F. Garrity, C. R. Brandt, C. S. Schobert, G. S. Feng M. W. Taylor, J. M. Carlin, and G. I. Byrne. 1993. IFN- $\gamma$-mediated antimicrobial response: indoleamine 2,3-dioxygenase-deficient mutant host cells no longer inhibit intracellular Chlamydia spp. or Toxoplasma growth. J. Immunol. 150:55295534.

55. Kanei-Ishii, C., A. Sari, T. Sawazaki, H. Nagakosi, D. He, K. Ogata, Y Nishimura, and S. Ishii. 1990. The tryptophan cluster: a hypothetical structure of the DNA-binding domain of the myb protooncogene product. J. Biol. Chem. 265:19990-19995. 